Research Paper

\title{
A Comparative Study on Morphochemical Properties and Osteogenic Cell Differentiation within Bone Graft and Coral Graft Culture Systems
}

\author{
Subramaniam Puvaneswary, Hanumantha Rao Balaji Raghavendran, Nurul Syuhada Ibrahim, Malliga \\ Raman Murali, Azhar Mahmood Merican, T. Kamarul ${ }^{凶}$ \\ Tissue Engineering Group (TEG), Department of Orthopaedic Surgery, NOCERAL, Faculty of Medicine, University of Malaya, Kuala \\ Lumpur-50603, Malaysia.
}

$\triangle$ Corresponding author: Dr. T. Kamarul, Deputy Dean (Research), Tissue Engineering Group, NOCERAL, Faculty of Medicine University of Malaya. 03-79492061 or 03-79494642 tkzrea@um.edu.my.

(c) Ivyspring International Publisher. This is an open-access article distributed under the terms of the Creative Commons License (http://creativecommons.org/ licenses/by-nc-nd/3.0/). Reproduction is permitted for personal, noncommercial use, provided that the article is in whole, unmodified, and properly cited.

Received: 2013.04.17; Accepted: 2013.08.30; Published: 2013.09.14

\begin{abstract}
The objective of this study was to compare the morphological and chemical composition of bone graft (BG) and coral graft (CG) as well as their osteogenic differentiation potential using rabbit mesenchymal stem cells (rMSCs) in vitro. SEM analysis of BG and CG revealed that the pores in these grafts were interconnected, and their micro-CT confirmed pore sizes in the range of 107-315 $\mu \mathrm{m}$ and 103-514 $\mu \mathrm{m}$ with a total porosity of $92 \%$ and $94 \%$, respectively. EDS analysis indicated that the level of calcium in CG was relatively higher than that in BG. FTIR of BG and CG confirmed the presence of functional groups corresponding to carbonyl, aromatic, alkyl, and alkane groups. XRD results revealed that the phase content of the inorganic layer comprised highly crystalline form of calcium carbonate and carbon. Atomic force microscopy analysis showed CG had better surface roughness compared to BG. In addition, significantly higher levels of osteogenic differentiation markers, namely, alkaline phosphatase (ALP), Osteocalcin (OC) levels, and Osteonectin and Runx2, Integrin gene expression were detected in the CG cultures, when compared with those in the BG cultures. In conclusion, our results demonstrate that the osteogenic differentiation of rMSCs is relatively superior in coral graft than in bone graft culture system.
\end{abstract}

Key words: Osteogenic, Porous materials, Tissue engineering, Biomaterial, Coral graft, Microstructure.

\section{Introduction}

Three-dimensional (3D) scaffolds such as bone graft and coral graft have received much attention in tissue engineering field due to its promising properties. The 3D architecture of these scaffolds in which cells interact with other cells and the extracellular matrix (ECM) offers supportive roles in addition to its enhanced cellular responses [1]. In stem cell therapies and tissue engineering, various types of scaffolds are prepared using natural polymer, synthetic polymer, and bioceramic material by employing emulsion freeze-drying method, porogen leaching method, and phototyping [2].
The exoskeleton of these high-content calcium carbonate scaffolds has been shown to be biocompatible and biodegradable at variable rates depending on their porosity, implantation site, and species [3]. Coral grafts act as an adequate carrier for growth factors and allow cell attachment, cell growth, cell differentiation. Coral graft has been reported to be non-genotoxic and biologically inert. Bone grafts have been used as a gold standard for tissue engineering applications, although several studies have reported limitations such as pain at the donor site and limited donors [4]. A previous study has reported the upreg- 
ulation of gene expression in CG seeded with human osteoblast cell line CRL 1543 in vitro [5]. However, to our knowledge, a comparative study on morphochemical properties and osteogenic cell differentiation potential of BG and CG using rMSCs has not yet been carried out.

\section{Materials and Methods}

\section{Scaffold preparation}

Briefly, Dead Sea coral of Porites species processed using lab standardized protocol. Coral skeleton material were cleaned from debris and washed with distilled water several times. Coral was cut and processed into granules and blocks with different dimension according to the requirements of the study, which had a mean cubic diameter 4.0-5.0 mm X 4.0$5.0 \mathrm{~mm} \times 4.0-5.0 \mathrm{~mm}$. For bone graft, fat and tissue free bone were cut into desired size and shape. After several washing using sterile water samples were centrifuged several times with vigorous shaking. These cubical were treated chemically followed by freeze drying. The samples were triple packed and radiosterilized at Malaysian Nuclear Agency using gamma irradiation under permissible limits. The integrity of the scaffold before and after was also confirmed using analytical techniques. Quality control test was performed to ensure the consistency of the scaffold.

\section{Rabbit bone marrow isolation and seeding}

Bone marrow derived mesenchymal stem cells (rMSCs) were harvested from 3-month-old New Zealand White rabbits using lab standardized protocol. Aliquots of 40-60 $\mu \mathrm{l}$ of cell suspension were seeded $\left(2 \times 10^{4}\right.$ cells $\left./ \mathrm{cm}^{2}\right)$ onto the top of each scaffold $(n=5)$ placed in 48 multi-well plates. A volume of $100 \mu \mathrm{l}$ of the medium was added to each well. The scaffolds were incubated for $12 \mathrm{~h}$ to allow the cells to attach to its surface, and were cultured using commercial Stempro Osteogenesis Differentiation Kit (Invitrogen Cell Culture, USA).

\section{Scanning electron microscopy (SEM) \& Energy dispersive spectroscopy (EDS)}

The specimens were fixed overnight in $4 \%$ glutaraldehyde in $0.1 \mathrm{M}$ calcodylate buffer and post-fixed for $1 \mathrm{~h}$ in $1 \%$ aqueous osmium tetraoxide. The processed specimens were examined using a digital SEM (JSM 6400; JEOL, Tokyo, Japan). EDS (10-30-kV INCA Energy 200, Oxford Inst.) spectrum was plotted using X-rays emitted from the specimens using Microanalysis Suite software version 4.05 (Oxford Inst.).

\section{X-Ray diffraction (XRD) \& Atomic force mi- croscopy (AFM)}

XRD patterns were recorded on a D8 Advance X-Ray diffractometer (D8 Bruker-AXS, USA) using Ni-filtered $\mathrm{Cu} K_{\alpha}$ monochromatized radiation at $40 \mathrm{kV}$, $40 \mathrm{~mA}$, and $25^{\circ} \mathrm{C}$. The $2 \theta$ range from 20 to $40^{\circ}$ was covered at a scan speed of $0.1 / \mathrm{min}$. The mass fractions were calculated and diffractograms were generated using DIFFRACplus-EVA software. Following critical point drying of samples, atomic force microscopy (NT-MDT Slover Next, Russia) with a feedback gain below 1 with $1.00 \mathrm{~Hz}$ probe frequency was used. The surface topography, 3D image were read using Nova Px 3.2.5 software.

\section{Fourier Transform Infrared Spectroscopy (FTIR)}

The scaffolds were crushed and pressed to obtain thin circular wafer using KBr. FTIR (IFS 66v/s Bruker, USA) spectra were recorded at a range of $4000-400 \mathrm{~cm}^{-1}$.

\section{Microtomography}

The samples were scanned at $20 \mu \mathrm{m}$ voxel resolution with an integration time of 120 microseconds using micro-CT system (SkyScan 1076, Belgium). Porosity and pore sizes were measured from the constructed 3D model of the coral and bone grafts.

\section{Confocal Microscopy}

Scaffold seeded with mesenchymal stromal cells were stained with Hoechst dye and analysed using confocal microscopy (Leica TCS-SP5 II, Leica Microsystem, Mannheim, Germany) after 20 min incubation at room temperature. The 3D image obtained from incorporation of multiple series of images collected by confocal laser further assisted the investigation of cell infiltration up to $300 \mu \mathrm{m}$ into scaffolds.

\section{Alkaline Phosphatase Assay (ALP) and Oste- ocalcin Assay (OC)}

ALP activity was assessed based on the hydrolysis process of $p$-nitrophenyl phosphate to $p$-nitrophenol using an assay kit (Abcam, USA) and OC using a commercial ELISA kit (IBL International, Germany).

\section{Gene expression}

The total RNA was isolated from BG and CG for one week after culturing in osteogenic medium to monitor early trends of gene expression. The samples were washed with 1X PBS and incubated for $4 \mathrm{~min}$ in Versene solution (Invitrogen), and then vortexed gently. The supernatants of all the sample groups were collected and the RNA from the collected su- 
pernatants was isolated using an RNeasy Mini Kit, according to the manufacturer's instructions. Subsequently, $1 \mu \mathrm{g}$ of RNA was used to generate cDNA using the Superscript III First Strand Synthesis Kit, according to the manufacturer's instructions. Primers for beta catenin, bone morphogenic protein 2 (BMP-2), integrin, osteonectin (OC), Runx2 were designed using NCBI database (USA) prior to q-PCR (Table 2). After an initial denaturation step at $95^{\circ} \mathrm{C}$ for $3 \mathrm{~min}$, the cDNA products were amplified with 40 PCR cycles, consisting of a denaturation step at $95^{\circ} \mathrm{C}$ for $30 \mathrm{~s}$, annealing temperature ranging from 50 to $60^{\circ} \mathrm{C}$, and an extension step at $72^{\circ} \mathrm{C}$ for $5 \mathrm{~min}$. The relative quantification values were analyzed using the Bio-Rad CFX manager 2.0. The level of expression of each target gene, normalized to housekeeping gene where $E_{t}$ is the amplification efficiency of the target sequence.

\section{Statistical analysis}

The results were expressed as mean \pm SDs and concentrations were analysed by SPSS v.16.0 (SPSS Inc., Chicago, IL) using one-way ANOVA followed by post-hoc LSD, with a significant level set at $p<0.01$.

\section{Results and Discussion}

The use of BG and CG scaffold in tissue engineering applications has gained considerable interest due to its biocompatibility and absorbability properties [6]. In this study, we tested coral graft to determine its potential in enhancing osteogenic differentiation of rMSCs under in vitro conditions. To prove the properties of 3D scaffolds, first, the characterization criteria such as morphology (e.g. porosity, pore size, and surface area) as well as mechanical and surface properties were examined. SEM analysis revealed that the pores in the CG were interconnected and their size ranged from 107 to $315 \mu \mathrm{m}$ (Fig. 1A \& Fig. 1C). On the other hand, the pore diameters for the bone graft were found to be 103-514 $\mu \mathrm{m}$, indicating that the scaffold environment was sufficiently large to accommodate stromal cells. Cell attachment on the scaffold was observed to be randomly distributed within the pore, which had roughened blebs and protrusions on the scaffold surface (Fig. 1E \& Fig. 1G). This observation is in agreement with the findings reported in previous studies, demonstrating that osteoid cells can colonize in pores of $40-100 \mu \mathrm{m}$ diameter. It has been previously reported that osteoblast-like behavior such as cell attachment efficiency, spreading, fiber formation, and cell migration is dependent on the surface chemistry of any material, which, in the present study, appears to be positive [7].

Micro-CT results confirmed large interconnecting paths in CG, especially, the nature of pore arrangement that appears to be similar to that of can- cellous bone (Table 1). EDS analysis indicated the presence peaks for calcium in both CG and BG scaffolds. The level of calcium in CG was relatively higher than that in bone graft, which appears to be correlated with the enhanced osteogenic differentiation observed in the coral graft (Fig. 1B, Fig. 1D, Fig. 1F \& Fig. 1H). FTIR bands demonstrated a range of $1476 \mathrm{~cm}^{-1}$, corresponding to the carbonyl group which contributes to surface polarity, while the spectra of BG showed peaks corresponding to respective functional groups, as shown in Fig. 2A \& Fig. 2B. The XRD results confirmed that the phase content of the inorganic layer of BG and CG comprised highly crystalline form of aragonite (calcium carbonate) and carbon (Fig. 3A \& Fig. 3B). It must be noted that the mineral composition of bone is mainly HA and amorphous calcium phosphate associated with calcium carbonate, while that of coral is essentially calcium carbonate [8]. AFM confirmed that the average roughness of $C G$ was higher than that of BG (Fig. 4A \& Fig. 4B). The average roughness of the surface of BG was $10.228 \mathrm{~nm}$, whereas that of CG was $19.541 \mathrm{~nm}$. In addition to SEM analysis, the infiltration of cells into the scaffold material was confirmed using confocal microscopy. Confocal microscopy results demonstrated cell attachment and its random distribution on the surface of the scaffolds (blue spots). The 3D image obtained from the incorporation of multiple series of images collected by confocal laser further assisted the investigation of cell infiltration up to $300 \mu \mathrm{m}$ into the scaffolds (Fig. 4C \& Fig. 4D).

Table I. Micro-CT of bone graft and coral graft.

\begin{tabular}{lll}
\hline Micro-CT observations & BG & CG \\
\hline Closed Porosity $(\%)$ & 0.344 & 3.0 \\
Volume of open pore space $\left(\mathrm{mm}^{\wedge} 3\right)$ & 133.6 & 516.6 \\
Total volume of pore space $\left(\mathrm{mm}^{\wedge} 3\right)$ & 133.63 & 519.7 \\
Total Porosity $(\%)$ & 94.6 & 92.2 \\
\hline
\end{tabular}

Sample of scaffolds $20 \mu \mathrm{m}$ analyzed using micro-CT system showing closed and total porosity, $(\%)$, volume of open pore size and its volume $\left(\mathrm{mm}^{\wedge} 3\right)$.

Table 2. Primer sequences are from 5' - 3'.

\begin{tabular}{lll}
\hline Gene & Sequence & Length \\
\hline$\beta$-catenin F & TGTGGTCACCTGTGCAGCTGGA & 22 \\
$\beta$-catenin R & TGGCAGGCTCAGTGATGTCTTCC & 23 \\
BMP2 F & TGGCCCACTTGGAGGAGAAACA & 22 \\
BMP2 R & CGCTGTTTGTGTTTGGCTTGACG & 23 \\
RUNX2 F & CCGCCATGCACCACCACCT & 19 \\
RUNX2 R & CTGGGCCACTGCTGAGGAATTT & 22 \\
Integrin F & TGGGCGCTACTGTCATTTGGG & 21 \\
Integrin R & CTGGCATCGGGTAGCTAGAGGC & 22 \\
Osteonectin F & TTGCAATGGGCCACATACCT & 20 \\
Osteonectin R & GGGCCAATCTCTCCTACTGC & 20 \\
\hline
\end{tabular}

F- Forward primer. R- Reverse primer. 
(A)

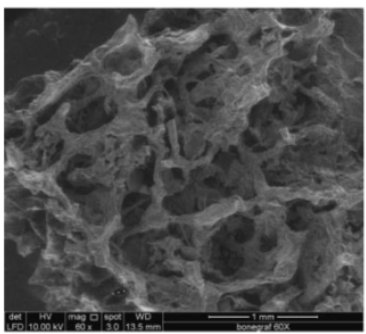

(C)

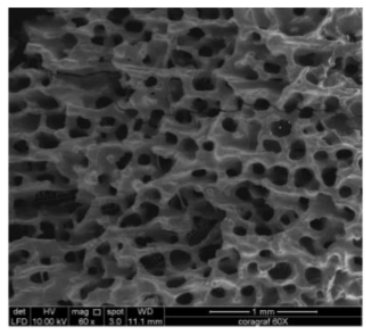

(E)

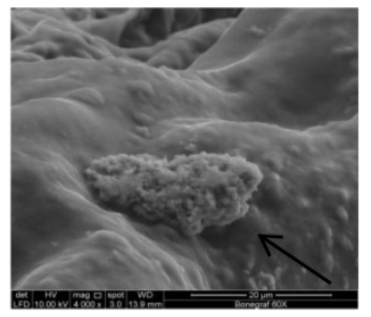

(G)

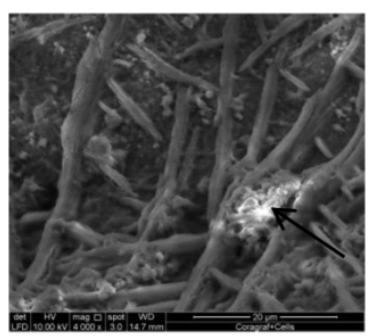

(B)

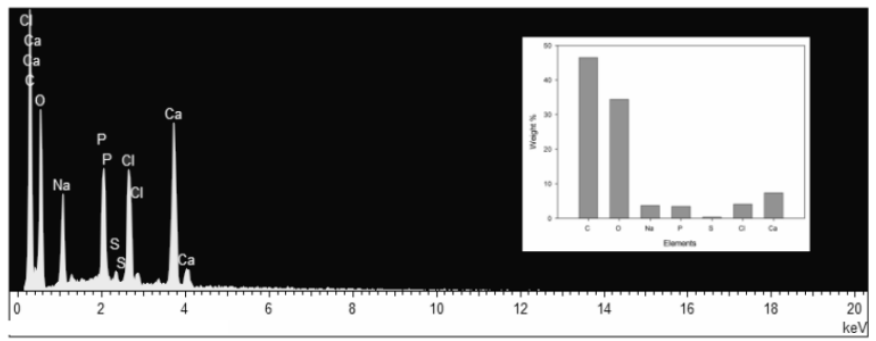

(D)

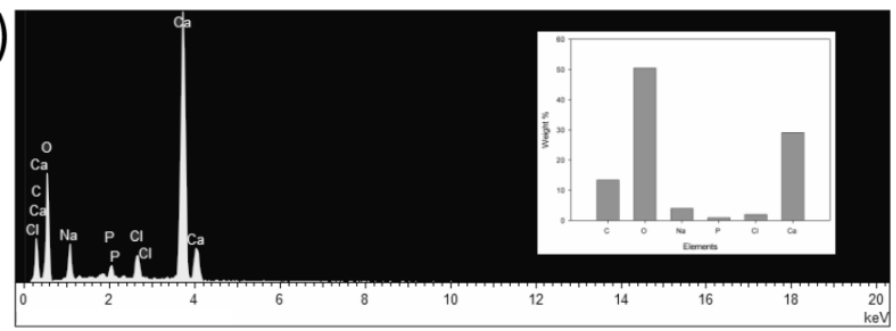

(F)

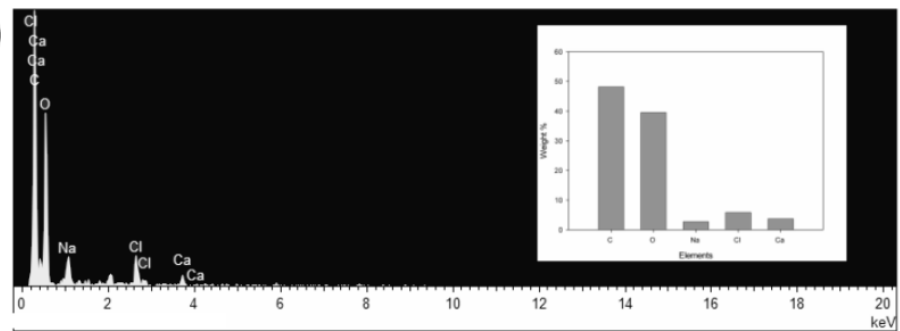

(H)

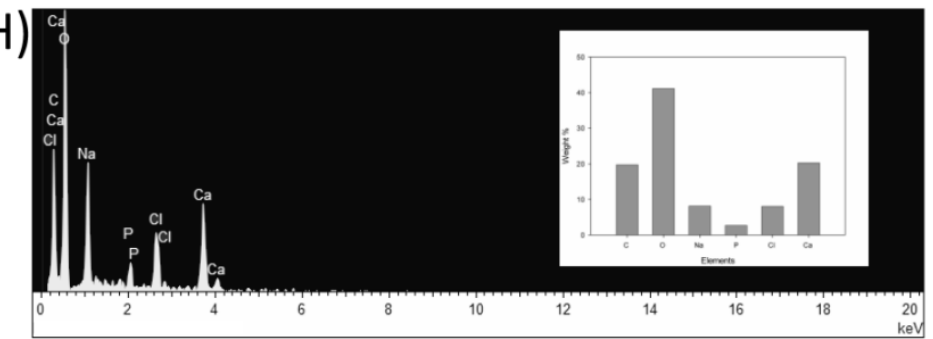

Fig I. SEM and EDX analysis of BG (A \& C) and CG (B \& D) without cells respectively. Cell attachment representative photographs of $B G(E \& G)$ and CG (F \& H) respectively, arrows indicate osteogenic like cells, (60x and 2000x).

(A)

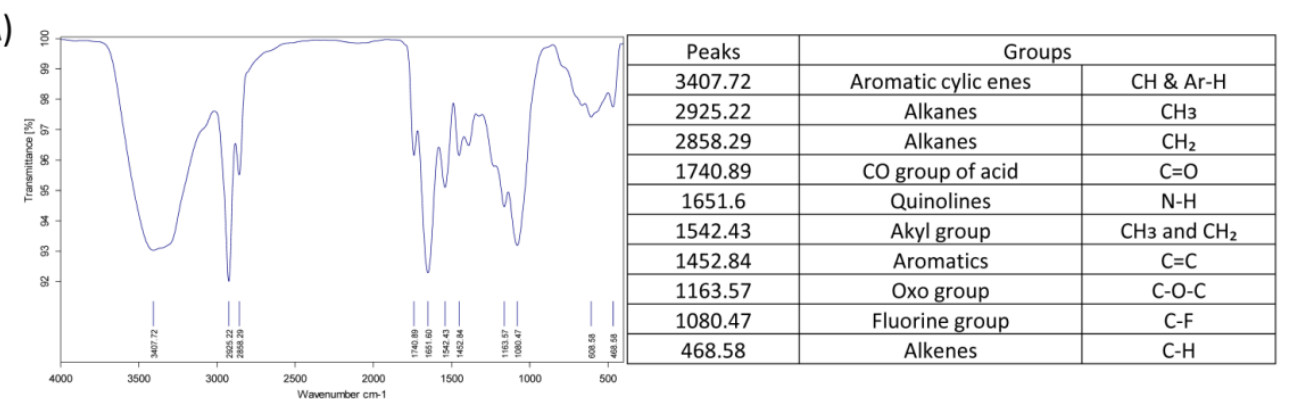

(B)

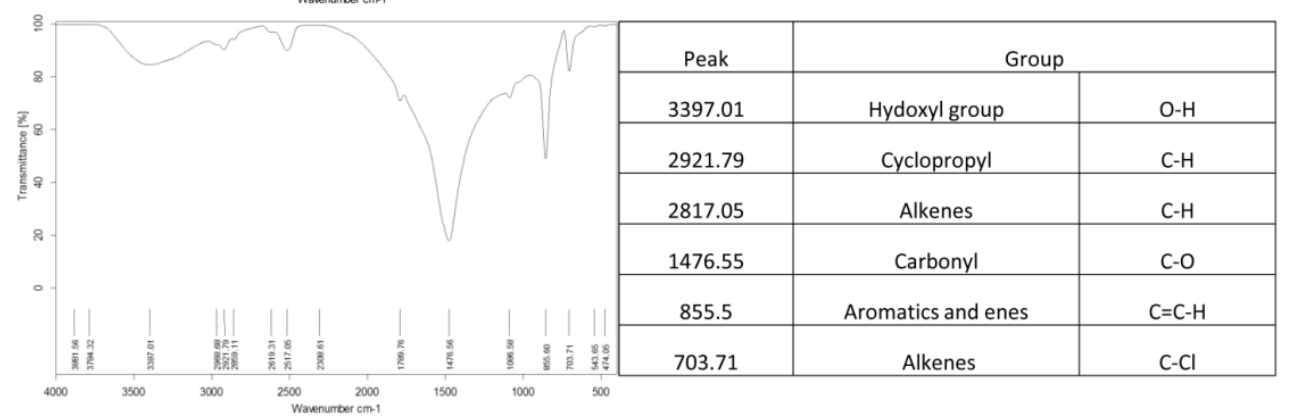

Fig 2. The functional groups of BG and CG using FTIR (A \& B). Scaffolds crushed and pressed with Kbr were analysed using FTIR. 
(A)

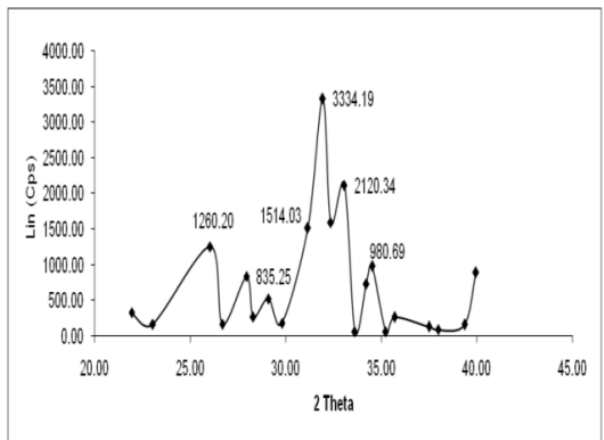

(B)

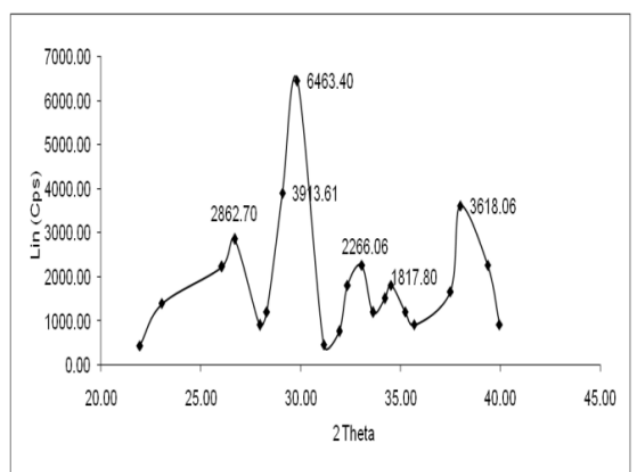

Fig 3. XRD pattern of $B G$ and $C G(A \& B)$. XRD patterns were recorded on a D8 Advance X-Ray diffractometer (D8 Bruker-AXS, USA) using Ni-filtered CuK $\alpha$ monochromatized radiation at $40 \mathrm{kV}, 40 \mathrm{~mA}$, and $25^{\circ} \mathrm{C}$. The $2 \theta$ range from 20 to $40^{\circ}$ was covered at a scan speed of $0.1 / \mathrm{min}$.

(A)

(C)
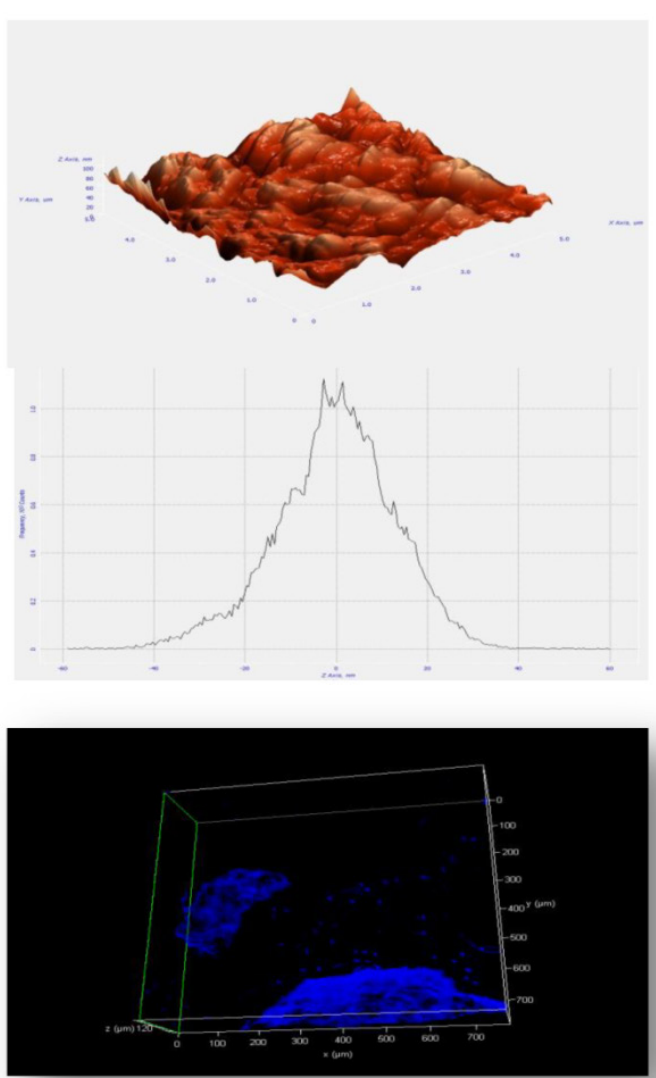

(B)

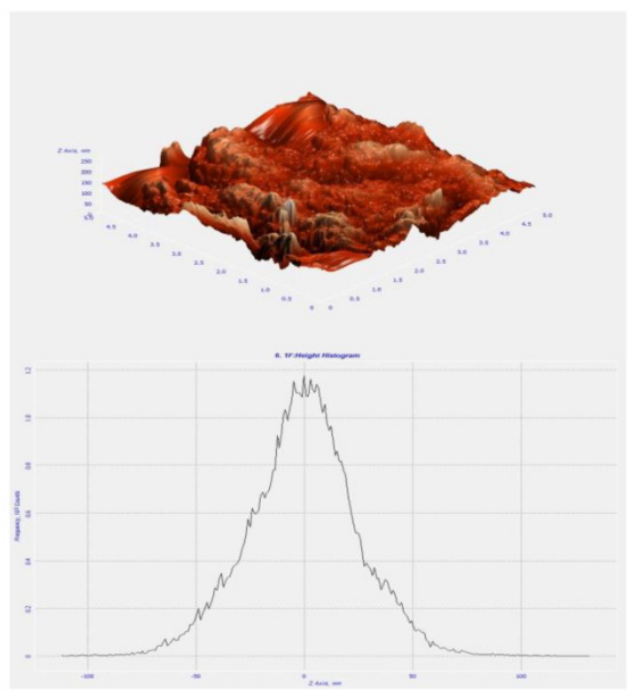

(D)

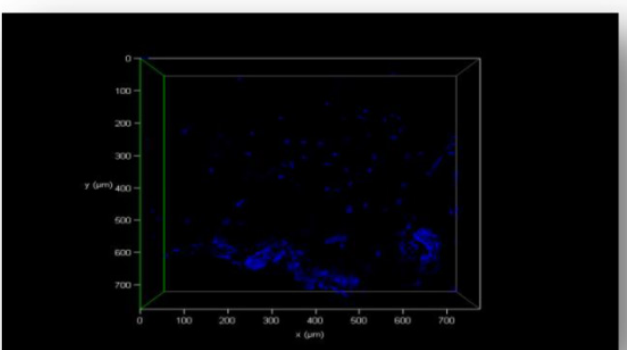

Fig 4. Atomic force microscopy of $B G(A)$ and $C G(B)$ without cells. The materials were subjected to critical point drying (CPD) and viewed using atomic force microscopy. The average surface roughness of the BG and CG were $10.10 \mathrm{~nm}$ and $19.54 \mathrm{~nm}$ respectively. (C \& D) Confocal miscroscopy examination of BG and CG at early time point. Positive staining (Blue spots) of indicates the penetration of cells inside the bone and coral graft.

Previous reports have shown that osteoblasts migrate faster into the larger pore of microcellular scaffolds, which provide the extra cellular matrix environment. However, pore size has not been observed to affect the depth of cell penetration or extent of mineralization. It has been reported that cell-scaffold binding can block pores of inadequate size and geometry. In addition, high interconnectivity of pores has also been found to be essential for the supply of nutrients and oxygen exchange in the inner regions of a scaffold to maintain cell viability, especially for complex tissue engineering of organs. In the present study, with regard to reproducibility, the number of samples used was six for in vitro culture assay, and four samples of each scaffold were used for the characterization study using FTIR, XRD, SEM, and Micro-CT. Overall, the results appeared to be statistically more or less similar for all samples examined. The statistical mean comparative analyses demonstrated no significant differences. Previous studies have reported that osteoblasts exhibited higher proliferation and elevated marker activity as well as OC expression on the rough surface than on the smooth one, which is correlated with the findings of the present study in 
which CG presented better expression of osteogenic marker and gene expression [9]. Depending on the scale of irregularities of the material surface, surface roughness can be divided into macro, micro, and nano roughness, each with its unique influence. The response of cells to roughness is different depending on the cell type. For larger cells, such as osteoblasts and neurons, macroscopic descriptions of the surface roughness could be reasonable [10, 11]. Nevertheless, the underlying mechanism, i.e., the role of pore size or surface of the scaffold structure and cell behavior, needs to be examined in detail in future studies.

ALP, an early-stage marker of osteogenic differentiation, was found to gradually increase and become two fold in cells cultured in the CG scaffold by day $18(P<0.01)$. Though a gradual increase in ALP was noted in cells cultured in BG, the increase was not as high. In CG culture, ALP production was significantly higher $(P<0.01)$ on day 27 (Fig. 5A). Studies have shown that SaOS-2cells grown for 25 days usually get detached from the culture, thereby limiting the assessment of ALP activity beyond 25-day time point [6]. In the present study, the production of OC, a late-stage marker of osteogenesis, was significantly enhanced $(P<0.01)$ in the CG culture approximately two fold increase in OC was observed in the supernatant of cells grown on CG on day 9, when compared with that noted in earlier time points. In contrast, it took 18 days for $\mathrm{OC}$ to reach high levels in the BG (Fig. 5B). A quantitative RT-PCR method was used to
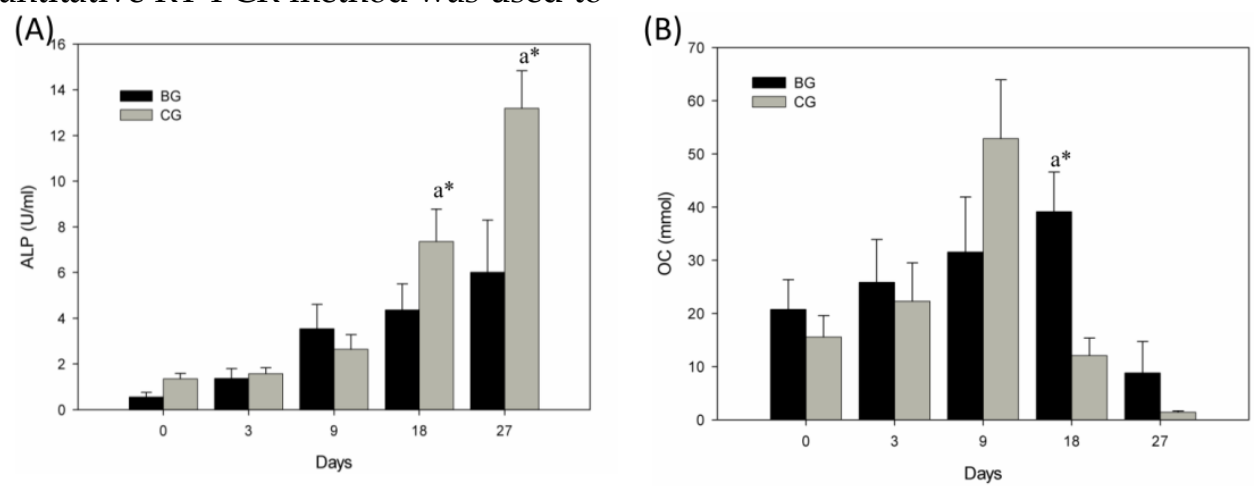

assess the gene expression (Fig. 5C) of osteoblasts at early time point (day 7). To determine whether early osteoblast differentiation was affected by BG or CG, we selected beta-catenin, BMP-2, integrin, osteonectin, and Runx-2 as markers for osteoblastic differentiation. Osteonectin is exclusively secreted by osteoblasts, is believed to play a role in metabolic regulation, and is pro-osteoblastic. It is also known as SPARC, a glycoprotein abundantly found in bone undergoing active remodeling process. In the present study, osteogenic differentiation was evidenced by the expression of osteonectin in CG induced with osteogenic differentiation medium. The genes encoding osteonectin are related to bone ECM formation. Osteonectin is synthesized by cells of the osteoblastic lineage, which binds to hydroxyapatite, calcium, and BG, and has been observed to assist inactive osteogenic differentiation of rabbit mesenchymal cells. Runx-2 gene is a member of the Runx-2 family of transcription factors and encodes a nuclear protein with a Runt DNA-binding domain. The protein can bind to DNA both as a monomer and, with more affinity, as a subunit of a heterodimeric complex. This protein has been implicated as a key transcription factor associated with osteoblast differentiation. As shown in Figure $5 \mathrm{C}$, significant differences could be observed in the gene expression between BG and CG on day 7 . The osteonectin expression was 5.5-fold higher on day 7.

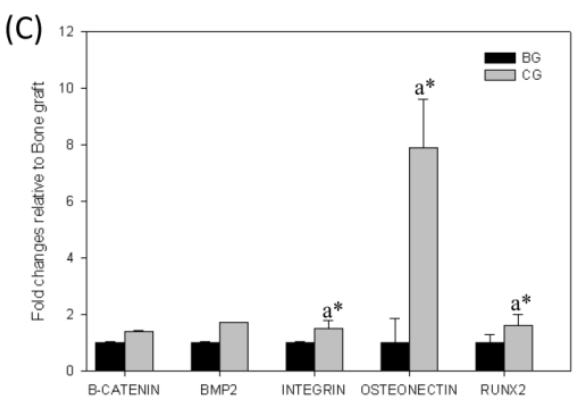

Fig 5. (A) ALP production in BG and CG and (B) osteocalcin production in BG and CG. Condition media collected at different time were subjected to ALP and OC assay using commercial kit $p<0.01$, a* CG Vs BG. Gene expression on early time point (Day 7) in bone graft and coral graft (C). cDNA products were amplified with 40 PCR cycles, consisting of a denaturation step at $95^{\circ} \mathrm{C}$ for 30 s, annealing temperature ranging from 50 to $60^{\circ} \mathrm{C}$, and an extension step at $72^{\circ} \mathrm{C}$ for 5 min. The relative quantification values were analyzed using the Bio-Rad CFX manager 2.0 
Furthermore, the Runx-2 expression was significantly higher day 7 in CG when compared to BG where as the expressions of other genes were relatively the same between BG and CG [12-14].In addition, the results obtained in the present study confirmed upregulation of integrin in early time point. It has been reported that integrin-mediated cell adhesion is involved in different cellular responses to the same environmental stimuli. Moreover, integrins also modulate cellular physiology by transmitting external mechanical stimuli into the cells. It has been observed that integrin could bind to its cognate ligand in the ECM molecules only after being activated by the G-protein-coupled receptors on the cell membrane. As integrins are considered to have diverse activities and densities in 300 different types of cells, various time periods have been noted for the cells to get attached and spread in the same micro environment [15].

In conclusion, the osteogenic differentiation potential of CG was found to be superior to that of BG. This suggests that coral graft may be a suitable material for future tissue engineering application when used with MSCs.

\section{Acknowledgements}

The authors are grateful to the Fundamental Research Grant Scheme FRGS (FP016) and HIRG-MOHE, University Malaya for supporting this study.

\section{Competing Interests}

The authors have declared that no competing interest exists.

\section{References}

1. Cukierman E, Pankov R, Stevens DR, et al. Taking cell-matrix adhesions to the third dimension. Science. 2001; 294: 1708.

2. Garg T, Singh O, Arora S, et al. Scaffold: a novel carrier for cell and drug delivery. Crit Rev Ther Drug. 2012; 29 : 1.

3. Demers C, Hamdy CR, Corsi K, et al. Natural coral exoskeleton as a bone graft substitute: a review. J Biomed Mater Eng. 2002; 12: 15-36.

4. Blackwood KA, Bock N, Dargaville TR, et al. Scaffolds for Growth Factor Delivery as Applied to Bone Tissue Engineering. Int J Polym Sci. 2012; 2012: 1-25.

5. Foo LH, Suzina A, Azlina A, et al. Gene expression analysis of osteoblasts seeded in coral scaffold. J Biomed Mater Res Part A. 2008; 87: 215-21.

6. Al-Salihi K. In vitro evaluation of Malaysian natural coral porites bone graft substitutes (CORAGRAF) for bone tissue engineering: A preliminary study. Braz J Oral Sci. 2009; 8: 210-16.

7. Webb K, Hlady V, Tresco PA. Relationships among cell attachment, spreading, cytoskeletal organization, and migration rate for anchorage-dependent cells on model surfaces. J Biomed Mater Res. 2000; 49: 362.

8. Combes C, Bareille R, Rey C. Calcium carbonate-calcium phosphate mixed cement compositions for bone reconstruction. J Biomed Mater Res Part A. 2006; 79: 318-28

9. Hatano K, Inoue H, Kojo T, et al. Effect of surface roughness on proliferation and alkaline phosphatase expression of rat calvarial cells cultured on polystyrene. Bone. 1999; 25(4): 439-45.

10. Hallab NJ, Bundy KJ, O'Connor K, et al. Evaluation of metallic and polymeric biomaterial surface energy and surface roughness characteristics for directed cell adhesion. Tissue Eng. 2000; 7(1): 55-71.
11. Krishnamurithy G, Murali MR, Hamdi M, et al. Characterization of bovine-derived porous hydroxyapatite scaffold and its potential to support osteogenic differentiation of human bone marrow derived mesenchymal stem cells. Ceramic International. 2013; In press.

12. Mundlos S, Otto F, Mundlos C, et al. Mutations involving the transcription factor CBFA1 cause cleidocranial dysplasia. Cell. 1997; 89: 773-9.

13. Kelm RJ, Swords NA, Orfeo T, et al. Osteonectin in matrix remodeling. A plasminogen-osteonectin collagen complex. J Biol Chem. 1994; 269:30147-30153.

14. Karsenty G. Bone formation and factors affecting this process. Matrix Biol. 2000; 19:85-9.

15. Xiao G, Gopalakrishnan R, Jiang D, et al. Bone morphogenetic proteins, extracellular matrix,and mitogen-activated protein kinase signaling pathways are required for osteoblast-specific gene expression and differentiation in MC3T3-E1 cells. J Bone Miner Res. 2002; 17:101-10. 